\title{
CARACTERÍSTICAS DEL DISCURSO EN LAS MEMORIAS ESPAÑOLAS DEL SIGLO XIX (1875-1914) ${ }^{1}$
}

\section{Aurora Mateos Montero}

En los estudios consagrados a la teoría general del relato y de su tipología, se observa un interés creciente por la literatura autobiográfica y los géneros que la integran. En el presente artículo, que en modo alguno pretende ser exhaustivo, se ofrece una caracterización de un tipo de relato ${ }^{2}$ o discurso: el discurso memorialístico. Lo hacemos describiendo la forma que presentan unos textos concretos: las memorias españolas publicadas en la época de la Restauración borbónica (18751914), cuyos títulos se dan en un apéndice.

Los trabajos teóricos que nos han servido de guía han sido los de Barthes (1967), Genette (1983 y 1989), Lejeune (1975), Lozano (1987) y Mussarr-Scrøder (1981), entre los dedicados a la semiótica y la narra-

\footnotetext{
1 Este artículo procede del capítulo «El discurso memorialístico», de mi tesis doctoral Memorias del siglo XIX (1875-1914) como fuente de información lingüística y literaria, leída en el Departamento de Filología Hispánica de la Universidad de Barcelona, en octubre de 1993 (A. Mateos, 1994).

2 Entendemos por relato, siguiendo la definición de Genette: «el enunciado narrativo, el discurso oral o escrito que entraña la relación de un acontecimiento o una serie de acontecimientos» (Genette, 1989: 81).
} 
tología; y los de Benveniste (1988) y Jackobson (1966) como dos de los estudios esenciales en el campo de la Lingüística.

Roland Barthes, en su artículo «Le discours de l'Histoire», que puede considerarse pionero en los estudios y análisis del discurso, se pregunta cuál es la diferencia entre la narración histórica y la narración imaginaria, ya que en tanto que artificio verbal no se distinguen una de otra. Si existe algún rasgo específico, alguna pertinencia indudable «¿en qué lugar del sistema discursivo, en qué nivel de la enunciación es necesario situarla?» (Barthes, 1967: 65). Es en el nivel de la enunciación donde, según el semiólogo francés, hay que buscar los rasgos pertinentes de un tipo de discurso.

En las memorias, al igual que en todo relato en primera persona, la narratividad está subordinada a la posición explícita, en el relato mismo, de un sujeto narrador que dice yo. Implican, por definición, referencia a un sujeto que escribe su historia, la historia de la que ha sido testigo, espectador o actor (Lozano, 1987: 206). Las memorias constituyen un tipo de enunciado que no se deja descifrar sin tener en cuenta quién lo enuncia y la situación en que lo enuncia. "Yo nací... en tal sitio»; ese yo es identificable por referencia al autor; y el pasado ya transcurrido de la «acción» contada lo es por relación al momento en que lo cuenta. Recogiendo los términos conocidos de Benveniste, podemos decir que la historia va acompañada aquí por una parte de discurso. Hay que subrayar que, en ningún texto, el nivel de la historia se realiza de una manera pura. Como afirma Genette, no existe el relato sin narrador, sino que todo relato es discurso, el enunciado sin enunciación es una pura quimera: «Dans le récit le plus sobre, quelque'un me parle, me raconte une histoire, $m$ 'invite à l'entendre comme il la raconte, et cette invite -confiance ou pression-constitue une indéniable attitude de narration. [...]. De fiction ou d'histoire, le récit est un discours, avec du langage on ne peut produire que du discours...» (Genette, 1983: 68).

Es precisamente de Genette de quien hemos tomado, más directamente, el marco teórico para la descripción del discurso memorialístico. De todas las categorías que el autor francés establece en su análisis el relato, nos fijaremos únicamente en la categoría de la voz, cuya definición es la siguiente: las determinaciones que se refieren a la forma como se encuentra implicada en el relato la propia narración. Entendiendo por narración la situación o instancia narrativa productora del discurso narrativo - sentido paralelo al de la enunciación lingüística-, y con ella sus dos protagonistas, el narrador y su destinatario. 
Dividiremos el análisis en tres apartados, partiendo de los elementos de definición de Genette, ligeramente modificados: determinaciones espacio-temporales, persona y funciones del narrador.

\section{DETERMINACIONES ESPACIO-TEMPORALES}

\section{Determinaciones espaciales}

Las determinaciones temporales de la instancia narrativa son más importantes que las espaciales. «Puedo perfectamente contar una historia sin precisar el lugar desde donde la cuento, mientras me resulta casi imposible no situarla en el tiempo en relación con mi acto narrativo, ya que debo necesariamente contarla en un tiempo del presente, del pasado o del futuro" (Genette, 1989: 273).

En las memorias que constituyen nuestro corpus, las determinaciones espaciales de la narración no suelen aparecer expresas; los autores no explicitan el lugar donde se produce el acto narrativo. No deja de haber excepciones, como es el caso de Echegaray, a quien sí le gusta decir, a veces, el lugar en el que se encuentra en el momento de escribir los artículos que constituyen sus larguísimos Recuerdos: «En Marín (Pontevedra) escribí el capítulo anterior. En Madrid, provincia de idem, voy a dictar este capítulo» (Echegaray, t. II: 81).

Otra cosa es la precisión del espacio de la historia narrada. Las precisiones del lugar de los acontecimientos (ciudades, calles, locales, casas) son tan abundantes en los libros de memorias como en cualquier relato novelesco. La diferencia radica en que, en los relatos de ficción, los nombres de los lugares pueden coincidir o no con los nombres reales. Es un rasgo no pertinente. En cambio, en las memorias, los lugares donde se desarrollan los acontecimientos son siempre lugares que existen, o han existido, en la realidad. No creemos necesario dar ejemplos de una característica tan evidente. 


\section{Determinaciones temporales}

Respecto a la posición temporal del narrador en relación con la acción contada, las memorias son un tipo de relato de narración ulterior, según la tipología de Genette. Los autores de memorias cuentan los acontecimientos de su vida pasada, anteriores al momento de la narración o enunciación. De ahí el continuo contraste del uso de los tiempos pretéritos (el pretérito indefinido y el pretérito imperfecto) en los segmentos narrativos que corresponden a la historia de los acontecimientos vividos por el yo narrado con el presente del acto de enunciación del yo narrante.

En los libros de memorias el tiempo de la historia viene marcado de forma tan insistente que las fechas concretas en que tuvieron lugar los acontecimientos narrados sirven frecuentemente de epígrafes a los distintos capítulos en que aparece organizado el discurso. Así, Mesonero Romanos distribuye la materia narrativa de sus Memorias de un setentón en etapas o fechas clave de los acontecimientos históricos más importantes de los que fue testigo siguiendo un orden cronológico, de tal manera que los epígrafes de sus capítulos aparecen fechados: «I. El 19 de marzo (1808)», «II. El 2 de mayo (1808)», «III. Del 2 de mayo al 4 de diciembre (1808)», y así sucesivamente. Lo mismo hace Nicolás Estévanez al articular sus memorias: «I. De la primera instancia (1838-1852)», "II. Ingreso en la academia militar (18531856)», "III. De oficial en el Regimiento de Zaragoza (1856-1857)». Las determinaciones temporales de la historia narrada no sólo aparecen en los epígrafes, sino que en el relato mismo son frecuentemente marcadas. Tomemos algunos ejemplos de estos mismos memoriógrafos ${ }^{3}$ : «...hasta que en la tarde del domingo, 1 de mayo, regresó a casa muy agitado...» (Mesonero: 48), «Las diez, poco más o menos serían de aquella mañana...» (Ibidem: 49), «Por fin, el día 4 de marzo, rompió el silencio...» (Ibidem: 1976), «En noviembre de 1852 salí de Santa Cruz en el vapor Riánzares [...]. Y el 2 de enero de 1853 senté plaza en Toledo... (Estévanez: 22).

El tiempo de la narración — del acto de enunciación-, en la mayoría de los relatos literarios, no suele aparecer fechado, salvo en raras excepciones. En cambio, a los autores de memorias les gusta datar la

3 Empleamos este término incorporado recientemente en el DRAE, en su vigésimo primera edición, a instancias de Pere Gimferrer, según confiesa él mismo en una entrevista a EL PAÍS, Babelia, 11 de marzo de 1995. 
instancia narrativa, que coincide, en este caso, con la instancia de escritura o de dictado. Se puede afirmar que el tiempo de la narración aparece frecuentemente marcado en los libros de memorias. Esto lo suelen hacer los autores de distinta forma:

I. En las memorias que fueron publicadas en la prensa periódica, el tiempo de producción del relato coincide con la fecha de escritura y publicación. Así ocurrió en los casos de P. de la Escosura, José M. Sanromá, Zorrilla, Echegaray, Luis Taboada o Galdós.

Veamos dos ejemplos: Patricio de la Escosura publicó los diez artículos que constituyen los Recuerdos literarios en La Ilustración Española y Americana, de enero a abril de 1876, y todos ellos aparecen con el nombre del autor y fecha al final. De manera que, cuando el autor habla en el primero, que sirve de introducción, del hoy, del presente o del ahora se está refiriendo a ese tiempo de enero del 76: «De ahí que, hasta ahora al menos, sean tan raros los libros referentes a la patria historia»; «... han de ser asunto de los artículos biográficos-literarios que escribir me propongo, y a que el presente deseo sirva de introducción y prólogo.»

Joaquín M. ${ }^{a}$ Sanromá publicó sus memorias en la Revista Contemporánea. El primer artículo salió el 30 de mayo de 1886, con firma del autor y fecha del 20 de mayo del mismo año: «Aquí la gran dificultad es la siguiente: manera de acercar entre sí los dos períodos más opuestos de la vida. Manera de traducir hoy las impresiones recibidas a una distancia de treinta o cuarenta años.»

II. En las memorias que han sido editadas en forma de libro, los autores datan el tiempo de la narración, en el interior del relato. Así, por ejemplo, lo hace D. Antonio Espina y Capo, quien publicó sus Notas del viaje de mi vida en 1926. En el capítulo III del tomo II, dice el autor: «... que aún hoy, 1926, nos viene entorpeciendo toda la política española». Julio Nombela escribió sus larguísimas memorias en distintos momentos de su vida y de algunos de ellos da cuenta en el discurso; dice en una ocasión: «En los momentos en que escribo estas líneas (junio de 1901) leo en los periódicos...» (p. 603).

Echegaray comenzó a publicar sus Recuerdos en La España Moder$n a$, en 1894, pero los acabó de publicar, pasado el año de 1906. De manera que los hoy de la narración corresponden a distintos años. La edición en libro, que es la que hemos manejado, es de 1917 y reproduce sin cambio alguno la versión de la revista, según advierte el editor. Las alusiones al tiempo de la narración son frecuentes. Así, en los pri- 
meros capítulos habla Echegaray del momento en que está escribiendo su relato como «... los últimos años del $\mathbf{s}$. XIX». En el capítulo XL (p. 161 del T. II), dice no recordar de qué hablaba en el artículo anterior por haber pasado «unos días muy agradables, pero de emociones continuas». Se está refiriendo a los homenajes recibidos a raíz de la concesión del premio Nobel (1905). Más adelante, al emprender la narración de unos acontecomientos que le ocurrieron en 1869 , dice recordarlos tan claramente como si le hubiesen ocurrido «el año de gracia de 1906, y en uno de sus hermosos días de otoño» (T. III, p. 4).

III. Otra forma que los autores emplean para datar el momento de la narración es mencionando la edad que tienen en ese momento: «Hoy que cuento más de 77 años...» (Echegaray: 345), «Hoy, a mis cincuenta y siete años de edad...» (Alcalá Galiano, Memorias...: 417).

En las memorias, el tiempo de la narración, el presente del acto comunicativo, coincide con una situación del autor-narrador, que es la misma en todos los autores: la vejez. Las fórmulas empleadas por los escritores que hacen referencia a estas circunstancias, que devienen así en tópico, presentan las siguientes manifestaciones: «Hallándome ya avanzado en edad y falto de ocupaciones, hame venido la idea de escribir mis recuerdos» (Conte); «Hay que perdonar a los viejos que conmemoren sus buenos o malos tiempos escribiendo sus memorias.» (Nombela); «Al mirar yo hacia atrás porque pertenezco al tiempo viejo...» (Zorilla); «Si a los viejos no nos recrean los recuerdos ¿para qué sirve el recuerdo? (Echegaray); «Un amigo mío [...] ha dado en la flor de amenizar su ancianidad cultivando el huerto frondoso de sus recuerdos.» (Galdós); «Cuando está uno en el duodécimo lustro de su existencia...» (Benalúa).

Para acabar este apartado de las determinaciones temporales, falta por analizar la distancia entre los dos tiempos, el de la historia y el de la narración.

En el relato de ficción en primera persona, la distancia temporal entre el momento de la narración y la afición contada es más explícita que en el relato en tercera persona (Mussarr-Scrøder, 1981: 5). Esta distancia entre las posiciones temporales del héroe-personaje y del héroe-narrador, es subrayada por las intervenciones de este último. «Lo más frecuente es que el narrador proyecte su conocimiento presente sobre su actualización del pasado al recrearlo», dice Alicia Yllera en su análisis sobre la novela autobiográfica (Yllera, 1981: 181).

Si esto se puede afirmar de la novela autobiográfica, de las memo- 
rias podemos decir que en ellas todavía es más explícita la distancia temporal entre el momento de la narración y la acción contada. He aquí algunos ejemplos; «iQué noche, Santo Dios! Setenta años se cumplen cuando escribo estas líneas...» (Mesonero: 51); «Cuarenta y tres años han pasado...» (Echegaray, T. II: 186); «Han transcurrido más de cincuenta y cinco años cuando escribo estas líneas...» (Nombela: 193).

La distancia entre los dos tiempos se va acortando a medida que avanza el relato ${ }^{4}$. La regla general de las autobiografías o de los relatos en primera persona, en los que el narrador es el personaje de la historia, consiste en una convergencia final entre la acción y la narración. Aunque esta es la regla clásica, lo que podemos denominar retrospectividad completa, algunos relatos autobiográficos presentan la realización particular de la retrospectividad: la retrospectividad fragmentaria (Mussarr-Scrøder, 1981:28).

En las verdaderas autobiografías, cuyo objeto es la historia de una personalidad y la verdad de sentido (Caballé, 1987: 175) ${ }^{5}$, la confluencia entre los dos tiempos parece obligada. Pero ¿qué ocurre en las memorias del s. XIX? En la mayoría, la confluencia de la acción narrada y de la narración no se produce. Son más frecuentes las memorias parciales que las totales. Se pueden distinguir las siguientes realizaciones:

A) Lo más frecuente es que los autores determinen, desde un principio, qué lapso de tiempo va a abarcar la historia narrada. Generalmente un lapso de tiempo que nunca llega hasta el momento de la narración, sino precisamente alejado del presente del acto comunicativo, el tiempo viejo.

Los autores que así han decidido contar solamente un período lejano de su vida lo suelen anunciar en las introducciones, lo reiteran a lo largo del relato y, a veces, lo vuelven a repetir al final del mismo. Mesonero Romanos anuncia en la introducción a sus memorias: «...en estos relatos que prepara - y que han de abrazar la primera mitad del

4 «Como en las memorias, el que sostiene la pluma y el que vemos vivir, distintos en el tiempo, tienden a juntarse; tienden hacia ese día en que la marcha del personaje en acción acaba en esa mesa en que el narrador, ya sin intervalo ni memoria, lo invita a sentarse junto a él para que escriban juntos la palabra: Fin» (Martín Chauffier, «Proust ou le double Je de quatre personnes», en Confluences, 1943, citado por Genette, 1989: 317 , nota 36 ).

5 La cuestión de los géneros que integran la literatura del yo ha sido tratada en los ya clásicos trabajos de Lejeune (1975) y Gusdorf (1991) y también ha sido uno de los temas que más interés ha despertado en nuestras letras, como lo demuestran los trabajos de Caballé $(1986,1987)$ y Romera Castillo (1980). Véanse también Anthropos 125 (1991), Suplementos Anthropos 29 (1991) y José Romera Castillo et alii (eds.), Escritura autobiográfica (1993). 
presente siglo, desde 1808 a $1850-\ldots »$ (p. 23). Al poner fin a su relato repite: «Y como en este mismo día [el 31 de diciembre de 1849] terminó también la primera mitad del siglo (en cuyo término dije en la introducción que habían de girar estas $M E M O R I A S$ ), pongo aquí fin a ellas...» (p. 396). Hay que advertir que Mesonero escribió sus memorias en 1879. Otro ejemplo: Zorrilla termina su narración después de contar los hechos de 1867 diciendo: «Aquí concluyen mis RECUERDOS DEL TIEMPO VIEJO, porque en aquella época concluyó el de mi poesía con el de mi juventud...» (T. II, p. 174).

Son también memorias fragmentarias - y mucho más breves- las siguientes: las de Patricio de la Escosura, que solamente reflejan la historia del trienio liberal; las de Fernández de Córdova, cuyo período narrado abarca desde el reinado de Fernando VII hasta el destronamiento de Isabel II; las de Eusebio Blasco, que narran el período comprendido entre 1861 y 1868; las de Federico Rubio y Galí, dedicadas a contar episodios de la infancia y la juventud; las de Barbasán y Laguernela, que cuentan los casos en los que el autor actuó de defensor desde 1876 a 1890; y las del Conde de Casa Valencia, con el relato de sus dos viajes a América $(1854,1856)$, entre otros ejemplos.

B) Otras memorias acaban en suspense. No presentan un final cerrado. Unas veces los autores manifiestan su intención de llevar la historia hasta el presente de la narración y prometen una continuación y fin, pero ese fin no llegó nunca. Es el caso de Nicolás Estévanez y de Joaquín M. a Sanromá, quienes prometen una segunda parte que nunca se publicó:

\begin{abstract}
«Al terminar esta primera parte de MIS MEMORIAS, sin saber cuándo publicaré la segunda ni siquiera si se publicará [...]».

«Lo intentaré, sin embargo, en la segunda parte de esta obra...» (Estévanez: 323-324).

«...rebasando el año de 1868 , que era el límite señalado a esta parte de mis MEMORIAS. Retrocedemos, pues, a nuestro 68, año de especiales acontecimientos para España; tan grandes y de tal importancia que exigen ser referidos, no en capítulo, sino en tomo aparte» (Sanromá, t. II: 413).
\end{abstract}

La convergencia final no se da tampoco en los Recuerdos de Echegaray. En este caso porque la muerte le impidió la continuación del relato hasta el momento de la narración, por tanto, ni siquiera existe promesa de continuación, se acaban bruscamente. 
C) La convergencia final entre la historia narrada y la narración se produce en un solo caso: en las memorias más completas y extensas -en cuanto al período narrado- de todas las que constituyen el corpus, las de Julio Nombela. La última de sus redacciones coincide con el final del período narrado (1912).

De esta revisión de las determinaciones temporales en el discurso memorialístico se puede concluir que la relación entre el tiempo de la historia y el tiempo de la narración está mucho más marcada, más explícita, que en otro tipo de relato ulterior.

La preocupación de los autores por datar en todo momento el tiempo de la historia es un elemento esencial cuya explicación hay que buscarla en el intento de ser fiel a la verdad. Es una estrategia de los autores para producir credibilidad en los lectores.

Las memorias del XIX presentan más frecuentemente una retrospectividad fragmentaria. Bien porque a los autores sólo les interesa una época determinada de su vida o de la historia pasada; bien porque abandonan el relato de las épocas más cercanas al momento de la narración por considerarlas demasiado conocidas por los lectores.

\section{PERSONA}

De los tipos de relato que Genette (1989: 298-299) distingue, según el estatuto del narrador por su relación con la historia, el relato de las memorias es de tipo autodiegético: el narrador es el protagonista de la historia narrada. Esta identidad entre narrador y protagonista se da en todos los discursos de carácter autobiográfico, incluidos los relatos de ficción. La especificidad de las memorias y de las verdaderas autobiografías no radica en esta identidad doble, sino en una identidad triple: narrador, autor y protagonista, como ha señalado Lejeune en su ya clásico estudio sobre el pacto autobiográfico (Lejeune, 1975).

La identidad de nombre entre autor, narrador y personaje puede ser establecida, según Lejeune, de dos maneras: a) implícitamente, en el nivel de la relación autor narrador, con motivo del pacto autobiográfico, bien con el empleo de un título ilustrativo: Historia de mi vida, Autobiografía, Memorias de..., Mis memorias íntimas; bien en un prólogo o texto inicial en el que el narrador se dirige al lector como si 
fuese el autor; y b) de manera patente, en el nivel del nombre que se da al narrador-personaje en el relato mismo (Lejeune, 1975: 147).

En las memorias que son objeto de nuestro estudio ¿cómo se marca formalmente esta triple identidad? La mayoría de las veces se marca de una forma clásica, con el uso del yo. No sorprende que se use la primera persona gramatical cuando se habla de asuntos privados. A pesar de ello, el yo resulta poco confortable cuando se habla de virtud o de buenos actos.

Las reflexiones que algunos autores hacen al respecto reflejan cierto desasosiego. Hablan del «miedo» que el uso del vocablo yo, del «satánico yo», les provoca:

«Pero el escollo verdaderamente formidable con que tropieza el autor de esta narracción histórico-anecdótica; el obstáculo que acorta y amengua el vuelo de su pluma, es la necesidad imprescindible, fatal, en que se encuentra de hablar en nombre propio, de usar el «satánico yo» (que diría su amigo Donoso Cortés), y de haber de combinar en cierto modo los sucesos extraños que relata con su modestísima biografía.

Esta circunstancia «sine qua non» (si ha de dar a sus narraciones las cualidades de veracidad y frescura que desea) es una pesadilla [...], se opone a su repugnancia hacia toda exhibición personal.

Mas ¿qué remedio? Dada la ocasión presente [...] no hay sino prescindir de pseudónimos y caretas, apellidar a cada uno con su nombre propio.

Hechas, pues, estas salvedades imprescindibles, y previa venia del lector, renunciando al socorrido «Nos» periodístico o archiepiscopal, procederé, desde luego, al ligero bosquejo que reclama el interés de la narración, de la vida íntima, de la manera de ser, como ahora se dice, de mi casa y mi familia...» (Mesonero: 25 ).

A pesar de esta declaración de principios, Mesonero no suele usar el yo - bien es verdad que sus memorias son poco íntimas-. Prefiere referirse a sí mismo con fórmulas de tercera persona del tipo: «el autor de estos apuntes retrospectivos», «el autor de estas Memorias», «mi humilde persona», «el autor de las Escenas Matritenses». Tan solo esporádicamente se atreve a usar la primera persona:

«Seguramente que al trazar este libro, por demás prosaico y limitado a una descripción más o menos amena, no pudo ser mi intento (y dejemos ya la narración en tercera persona) aspirar a un triunfo literario...» (p. 305). 
Echegaray muestra un sentido del humor más aguzado que el viejo setentón, y, así, resuelve el escollo del yo de una forma más airosa:

«Y mi repugnancia [al escribir sus Recuerdos] se explica, porque en esta empresa en que me he metido, o a que me he lanzado, voy a tener que emplear un vocablo que me asusta, y que más de una vez hará que me detenga o que vacile, como ahora vacilo, al terminar una frase o al cerrar un período.

Y este vocablo, que me aterra es el satánico, el vanidoso, el peligrosísimo Yo.

¿Qué remedio? El que cuenta, tiene que emplear de continuo este pronombre: yo vi esto; yo presencié esto; yo sufrí aquello; yo hice tal o cual cosa. Y siempre esta maldita primera persona ha de manchar con vahos y tufos de egoísmo o de solapada vanidad, cuanto se diga o cuanto se refiera.

Bienaventurados los ingleses, la raza individualista por esencia, que con suprema impasibilidad y sin escrúpulos ortográficos, escriben el $Y o$ con una $I$ mayúscula en todas partes, lo mismo en medio que al principio de un párrafo. El $I$ campea soberbio por todo el espacio del escrito, como alto campanario sobre míseras casuchas de pueblo.

No me siento yo con tamaño valor, que quisiera escribir el tenebroso vocablo con las más humildes y modestas letras del más diminuto abecedario». (Echegaray, t. I: 3-4).

Esta «repugnancia» que confiesa Echegaray al comienzo de sus Recuerdos parece ser más un recurso retórico del autor que una verdadera declaración de modestia. Insiste varias veces en ello. Primero dice que teme abusar del peligroso pronombre:

«Pero su esbeltez [la de la catedral de Murcia, donde pasó su infancia] vertical me recuerda en este momento la orgullosa $I$ británica, cuyo significado en español es Yo, como para hacerme notar que he abusado más de lo justo - si es que hay modo de abusar en justicia - del peligroso pronombre. Basta ya» (Echegaray, t. I: 12).

Un poco más adelante, añade:

«Es que yo, y véase cómo me voy familiarizando con el vocablo, y perdóneseme de paso la falta de modestia; y es que yo, repito, y lo repito a gusto, he tenido buena sangre para los demás» (Echegaray, t. I: 28).

En el resto del relato, Echegaray emplea el yo con toda tranquilidad: 
«Y ahora caigo en la cuenta de por qué mi memoria, que es tan rebelde, se muestra mansa en esta ocasión [...]. Es que en esta primera combinación yo voy a jugar un papel importante.

¡Ahí es nada!

Yo, que pocos meses antes me limitaba a explicar cálculo infinitesimal a una docena de alumnos [...].

Así como suena, Yo intervenía de una manera importante, en la obra difícil y grandiosa de fabricar un monarca para el trono vacante de San Fernando» (Echegaray, t. II: 250).

Eusebio Blasco también confiesa sentir cierto desagrado al usar el yo: "Y si abunda el yo, que siempre parece pretencioso...» (Mis memorias, p. 8).

A excepción de estos casos, la mayoría de los autores de las memorias estudiadas (Nombela, Zorrilla, Sanromá, Federico Rubio, Unamuno, Ramón y Cajal, Alcalá Galiano, Nicolás Estévanez, etc.) utiliza el yo, como es preceptivo en el género autobiográfico.

Hay que tener en cuenta que el «terrible vocablo» debe ser empleado con muy poca frecuencia en nuestra lengua, dado el carácter flexivo del verbo y dado que la norma de la lengua escrita recomienda no emplear el pronombre. De tal manera que en la mayoría de los casos -exceptuando los de necesidad de la lengua, por ejemplo en los de ambigüedad: «¿Qué hacía yo durante el día?» (Nombela: 24); «creía yo que mis ensayos...» (Galdós: 194); o en los de énfasis: «Es evidente que si yo no tengo hoy de mi madre...» (Rubio: 23) - los autores hablan de sí mismos introduciendo verbos en primera persona sin pronombre sujeto:

«Nací en la ciudad de Las Palmas...». «Desde que nací tengo instintos destructores...». «Englobo en mi cariño aquellas siete islas...». «Allí pasé la infancia.... (Estévanez: 20).

«Según oí decir en mi niñez ([...] nací en Madrid...». «Creo que no se nace verdaderamente hasta...». «No paso por la calle de la Luna sin dirigir una mirada...» (Nombela: 25).

«Doy comienzo a esta primera parte de mi existencia...». «Omito lo referente a mi infancia...». «Transido de dolor, les vi pasar...» (Galdós: 194).

El uso de la primera persona alterna, en otros autores, con el de la tercera, con fórmulas de humildad, como las que hemos señalado de Mesonero: «Mi humilde persona o personilla» (muy frecuentemente 
empleada por el Conde de Benalúa); «el autor de estas memorias», «el escritor de estas líneas»; o bien con fórmulas que aluden a aspectos del memoriógrafo: «Un joven pálido y melenudo», «El estudiantón», «El mozo aquel», «El viajero que ya conocéis», como hace Eusebio Blasco.

También hemos encontrado algún ejemplar del plural de modestia. Es el caso de Antonio Espina y Capo, quien realmente lo usa de manera exagerada: «Y nosotros hemos conocido arrepentidos a ambos redactores...» (t. I: 117), "Nuestro inolvidable y querido amigo...» (t. I: 119), «...donde estuvimos hasta el nombramiento de intendente...» (t. II: 156), «Los grandes escritores, como los modestos cronistas como nosotros, estamos conformes...» (t. II: 169), «Constituye para nosotros una sagrada obligación...» (t. II: 415).

Para terminar este apartado de la persona nos falta aludir a la dicotomía que establece Genette: Protagonista/narrador (Genette, 1989: 307). Según él, se podría hablar de dos voces: la del protagonista y la del narrador (los dos actantes que Spitzer llamaba «yo narrante» y «yo narrado»).

En las memorias ${ }^{6}$, esa diferencia de edad entre los dos tipos de yoes, el de tiempos pasados y el contemporáneo a la narración, se marca continuamente con el uso de las formas verbales /yo pensaba o yo creía/ frente al /ahora pienso o creo/, como ya se ha indicado al hablar de la distancia entre los dos tiempos. El yo narrante no es otro que el autor en la situación de edad avanzada, y así puede tratar al yo narrado, que no es uno, sino varios a lo largo de la dilatada vida, de «niño travieso que yo era», o de «el joven inocente que yo era entonces», frente al "viajero experimentado que soy ahora».

Echegaray, el autor que más reflexiona acerca de su actividad discursiva, dice:

6 Amado Alonso (1969: 356), dice al respecto: «Es fácil percibir la diferencia entre Diario y Memorias. En el Diario, las reacciones emocionales y valorativas del narrador forman parte de los actos mismos narrados. En las Memorias, se superponen obligatoriamente a los sucesos y a las reacciones anímicas que en su momento provocaron en el actor, las que ahora provoca en el autor la evocación de aquellos hechos lejanos; ahora contemplamos lo que entonces vivimos. Han cambiado nuestros conocimientos, nuestro organismo; la experiencia y los cambios biológicos nos han dado una visión del mundo distinta de la que teníamos entonces. Y el lenguaje de las Memorias reflejará superpuestas ambas visiones. [Sigue ejemplo de D. Segundo Sombra para reflejar esa opinión de dos mundos.] Las dos visiones del mundo, la de entonces y la de ahora, corren por el papel nítidamente paralelas». 
«Y observo que unas veces hablo en tiempo pasado, que es lo que al recuerdo corresponde, y otras en tiempo presente; pero es que, a decir verdad, para haber vivido tanto, yo no he variado mucho» (Echegaray, t. III: 26$)$.

« Quién sabe! Acaso es una aspiración a hacerse superior al espacio y al tiempo, recogiendo el que pasó y uniéndolo en rápida carrera al presente; aspiración a la unidad del espacio y el tiempo; aspiración a la inmortalidad» (Echegaray, t.III: 3).

Las dos voces pueden fundirse y confundirse, o alternarse en un mismo discurso. Ello se debe a la proliferación de funciones o papeles del narrador. De ello nos vamos a ocupar a continuación.

\section{FUNCIONES DEL NARRADOR}

Las funciones que Genette atribuye a cualquier narrador (Genette, 1989: 308-309) son las siguientes: función narrativa, función de control, función de comunicación, función testimonial y función ideológica (estas dos últimas se corresponden con la función emotiva de Jackobson). Examinaremos exclusivamente las cuatro últimas.

\section{La función de control}

El aspecto al que se refiere el narrador es el texto, al que el narrador puede referirse en un discurso en cierto modo metalingüístico para señalar sus conexiones, su organización interna. A esta función corresponden las marcas explícitas llamadas por R. Barthes (1967) «organizadores de discurso» o «indicaciones de control» por otros autores, $y$ que dan cuenta del movimiento del discurso en relación a su materia.

Hablar de la organización del discurso es una opción personal que en algunos autores de novelas es más abundante que en otros, y que, como dice Genette, en algunos llega a ser «indiscreta» (pone por ejemplo a Fenimore Cooper y Thomas Mann).

Los autores de las memorias estudiadas utilizan continuamente marcas explícitas para indicar cómo organizan su propio discurso o cómo modifican el curso del relato. En primer lugar analizaremos las mani- 
festaciones de los autores acerca de la organización general de su discurso; a continuación veremos los organizadores de discurso.

Se pueden distinguir dos formas distintas de organización general del discurso: a) el riguroso orden cronológico $-\mathrm{y}$ dentro de él, una ordenación temática-; y b) el desorden que impone la afluencia de los recuerdos a la memoria del autor.

a) La primera forma es la adoptada por la mayoría de los textos estudiados, en este caso llevan el título de Memorias. El orden cronológico, sigue el hilo de los acontecimientos históricos, etapa por etapa, como ocurre en toda narración clásica, la manera ortodoxa del relato ulterior. Así organizan su materia narrativa Mesonero Romanos, Alcalá Galiano, Nicolás Estévanez, Julio Nombela, Joaquín M. ${ }^{a}$ Sanromá y Antonio Espina y Capo, entre otros. Para demostrarlo bastaría echar una ojeada a los índices de estas memorias. Cuando el autor que ha elegido esta opción se aparta de lo prometido, pide disculpas a los lectores por ello.

b) La segunda forma, la de la afluencia de los recuerdos a la memoria, es la empleada por P. de la Escosura, Zorrilla y Echegaray, principalmente. En este caso, los autores han preferido el título de Recuerdos al de Memorias. Veamos las manifestaciones de estos autores al respecto. Conviene advertir que, de los tres, es Echegaray quien más veces interviene como narrador para dar cuenta de la organización general de su relato:

«A pesar de que, en el artículo que sirve de introducción a esta serie de mal hilvanadas Memorias de los primeros años de mi vida, he dicho terminantemente que en ellas no debe el lector, que no quiera llevarse un chasco, buscar nada que a una lógica consecutiva narración de sucesos se parezca, ni siquiera biografía alguna completa, todavía me es forzoso, en descargo de mi conciencia, insistir de nuevo en aquella mi muy sincera declaración. [...] Conste, pues, lo declarado, y resígnese el lector benévolo, si tiene el mal gusto de emplear el tiempo en enterarse del contendio de estos artículos, a considerar que asiste a una de esas exposiciones de cuadros disolventes, en que, cuando comienza a enterarse de que está mirando, por ejemplo, las pirámides de Egipto, súbito y sin transición racional se encuentra delante de sí el túnel del Támesis en Londres, o la Basílica de San Pedro en Roma, si a mano viene» (Escosura, art. III: 62).

«... ni estos recuerdos son memorias históricas, ni relación de impresiones de viaje, que obligan a seguir lógica y consiguientemente una narración; sino la consignación de mis ideas en un papel, según en mi imaginación desordenadamente se van presentando» (Zorrilla, t. I: 127).

«Porque estos mis desordenados RECUERDOS DEL TIEMPO VIEJO son una madeja de quebradizos y rotos hilos, de cuyos cabos voy tirando al azar según los voy devanando en el desigual ovillo de mis artículos de $E l$ 
Imparcial; y en éste veo que es preciso que dé a mis lectores, si tengo algunos, un cabo conductor y alguna luz que les guíe por el laberíntico relato de mis entradas y salidas por las puertas y escenarios de los teatros de la Cruz y del Príncipe. Mis RECUERDOS no son, desventuradamente para mí, una obra de cronológica ilación, de continuidad lógica y progresiva de bien enlazados sucesos, y de uniforme estilo, como las curiosas Memorias de un setentón del Sr. de Mesonero Romanos, [...] Mis RECUERDOS no pueden, ni intentan competir con sus Memorias; y cuando hoy se reducen a un libro con una más ordenada forma, aún no pueden parangonarse con aquellas» (Zorrilla, t. I: 168).

«[...] y tendré que contar el drama con el abandono y el desorden con que lo contaría en un círculo de amigos, que por amigos tengo a cuantos se digna leer estos recuerdos» (Echegaray, t. I: 295).

«Como voy dictando estos recuerdos sin plan preconcebido, sin orden cronológico, sino como ellos se van presentando, ordenada o desordenadamente, y por lo regular desordenadamente, a mi memoria, los sucesos a veces se mezclan y se confunden y aún se invierten.

Son como cerezas en un cesto, que al sacar una de las que están en la superficie, saca enredadas por sus dobles rabillos un pelotón de las cerezas que se agrupan en el fondo" (Echegaray, t. I: 369).

«Es algo así como una conversación conmigo mismo, en que salen desordenadamente por las puertas de lo pasado imágenes y sucesos en revuelta confusión, sin orden de fechas, sin enlace de ideas, sin nada que indique plan preconcebido o sistema cronológico» (Echegaray, t.II: 293).

«Y ya lo he dicho muchas veces: escribo sin orden ni plan, cediendo a los caprichos de la imaginación o del recuerdo, y andando y desandando el camino, a imitación de los perros, que son animales superiores, y que cuando tanto andan y desandan, su razón y su instinto tendrán para ello» (Echegaray, t. III: 3).

«Reuniendo mis recuerdos, y si otros recuerdos no se me cruzan en el camino, procurando coordinarlos, los expondré en el próximo capítulo; pero conste que no respondo de cumplir esta palabra, porque cuando de nuevo me ponga a dictar, yo no sé por dónde irá mi imaginación, no sé qué nuevos caprichos de la memoria me marcarán rumbo, y al volver la vista atrás, qué viejos horizontes de lo pasado aclararán sus nieblas ante mis ojos" (Echegaray, t. III: 48).

«Escribo a gusto estos recuerdos, como he dicho varias veces, por la ilimitada libertad con que los escribo.

Libertad en el plan; que más libertad no cabe, que no tener ninguno.

Libertad en el estilo [...]

Libertad en las fechas; que el recuerdo salta sin orden cronológico de una a otra, avanzando, retrocediendo, retrocediendo más, para dar un nuevo salto hacia adelante de unos cuantos años.

Libertad en el asunto, y tanto, que no hay asunto. Agitar el cerebro es lo que hago y coger al vuelo las ideas, que de él van desprendiéndose, si es que puedo cogerlas y no se pierden en el espacio [...]

Esta libertad, mejor dicho, este desorden, que será tal vez desesperación para el lector, es el mayor encanto para mí [...].

$\mathrm{Ni}$ sé lo que en el artículo anterior dije, ni sé lo que en éste diré: saldrá lo que saliere» (Echegaray, t. III: 143-145). 
Aparte de estas declaraciones de los autores acerca de la organización de su relato, hay que fijarse, para dar cuenta de la función de control del narrador, en los organizadores de discurso o indicadores de control: los signos declarados con los que los autores-narradores de memorias advierten de los movimientos del discurso en relación con su materia: parada, anuncio, subida y bajada (Lozano, 1987: 133).

La parada: El narrador interrumpe el curso del relato. La interrupción puede producirse momentáneamente, para reanudarse después; o bien de manera total. En el primer caso, se trata, la mayoría de las veces, de interrupciones que el narrador se ve obligado a hacer a causa de los límites impuestos por el medio y forma de publicación: el artículo periodístico:

«Pero este acontecimiento y sus resultados inmediatos no caben ya en los límites del presente capítulo y ofrecerán materia sobrada para el siguiente» (Mesonero, 87).

«Pero temiendo, bien lo sabe Dios, abusar de la paciencia del lector, hago un alto aquí, aplazando mi narración en este sentido para el capítulo siguiente, y pidiéndole me disculpe si en vez de un capítulo histórico-político, le ofrezco hoy solamente una semisecular y desaliñada gacetilla» (Mesonero, 325).

«Pero este artículo excede ya de las dimensiones ordinaria; proseguiremos otro día». (Escosura, art. VIII).

«Pero del francés que hablaba don Salustiano me ocuparé en otra ocasión, porque algo muy curioso tengo que decir [...].

Bueno es ir dejando de un capítulo a otro algún cabo suelto de curiosidad, aunque no llegue al de aquel folletín de Jerónimo Paturot: "de quién será aquella cabeza, de quién será aquel brazo"»(Echegaray, t. I: 172).

El narrador también interrumpe el acto comunicativo de forma provisional en las memorias que presentan forma de diario. Es lo que ocurre en algunos fragmentos de las de Antonio Vico, quien interrumpe frecuentemente el relato y lo indica con fórmulas conversacionales del tipo siguiente: «Hoy estoy cansado. Muy buenas noches», «Voy a fumar un cigarrito, a meterme en la cama, y mañana será otro día».

El movimiento de parada total, el «no diré más sobre este asunto», lo suelen emplear los autores de memorias en los siguientes casos: 1) en los momentos en los que la narración se refiere a sucesos que el narrador considera demasiado conocidos por los lectores: 
«Porque tratándose ya de sucesos coetáneos a la mayor parte de los vivientes y descritos minuciosamente en tantos libros de historia contemporánea, en tantos folletos, memorias y diarios que la prensa, emancipada ya, ha producido y comentado, ¿qué interés podría añadir a la narración de sucesos $\tan$ conocidos...?

Por estas y otras razones me callo» (Mesonero, 373).

2) En los acontecimientos considerados demasiado íntimos:

«Abreviemos este relato, sobre el cual deseo pasar sobre ascuas. Mis memorias son demasiado personales para inspirar interés, y demasiado íntimas para ser reveladas en vida" (Zorrilla, t. I: 52 ).

«No he de llevarlo hacia el lado de mis sentidas emociones; pasen en silencio, por cuanto que no importan al lector ni a mi propósito» (F. Rubio, 93).

«... pero, no; perdóneme el lector que guarde en el jardín misterioso de que tantas veces he hablado los recuerdos de aquella lucha y de aquel triunfo» (Nombela, 637).

«Tente, pluma. No quiero desagradar a sus hijos, hombres de orden que, probablemente, no han matado a nadie» (Estévanez, 188). [Acaba de contar la muerte del general Canterac a manos de un sargento cuyo nombre es el que calla.]

3) En aquellos asuntos que se escapan al propósito del narrador:

«Ni de esta ciudad [Cádiz] ni de la de Sevilla diré una palabra más; porque ni hay ya nada que de ambas en prosa o en verso no se haya dicho, ni estos recuerdos son memorias históricas, ni relación de impresiones de viaje» (Zorilla, t. I: 128).

«Dejando estas particularidades, si propias de mis MEMORIAS, nada a propósito para entretener a mis lectores...» (Alcalá Galiano, t. II: 188).

El anuncio: A modo de preparación de los lectores, los autores de memorias suelen anunciar la materia de la historia que se disponen a narrar. Son tantas las citas que podríamos aportar que, para no extendernos demasiado, ofrecemos solamente las fórmulas más frecuentes: «Esto es lo que vamos a ver en el capítulo siguiente» (Mesonero, 189); «... este animado teatro social es, pues, amados lectores, lo que hoy me propongo trazar en mi desaliñada narración» (Mesonero, 160); «De estos años mucho os tengo que decir» (Echegaray, t. III: 233); «Sobre este y otros temas análogos consignaré más adelante mis impresiones» (Nombela, 280); «... la votación del rey D. Amadeo de 
Saboya y la última sesión, que a continuación relataremos» (Espina, t. II: 216); «a él [Julián Romea] me he de referir en este momento» (Espina, t. II: 298).

Un caso híbrido entre indicadores de parada y de anuncio lo constituyen las fórmulas que los memoriógrafos emplean para anunciar el final de sus memorias, o, al menos, de la primera parte de ellas. Hay que tener en cuenta de nuevo que muchas de ellas se publicaron en revistas; de manera que, lo mismo que ocurría con las novelas por entregas, el narrador tiene que prevenir al lector, de manera expresa, de que con ese artículo pone punto y final a su narración: «Aquí concluyen mis Recuerdos del tiempo viejo» (Zorrilla, T. II:251); «Al terminar esta primera parte de Mis Memorias...» (Estévanez, 324).

La subida: El narrador hace referencia a momentos del relato posteriores en la organización del discurso, con fórmulas del tipo «como repetiré en otro lugar». Arrastrados por el flujo de los recuerdos, los autores de memorias llegan frecuentemente, en el relato de los acontecimientos, a un punto que les lleva a hablar de otros momentos posteriores -0 de otros personajes distintos al que están retratando o del que están hablando-. Entonces, casi sin querer, los mencionan de pasada para volver a hablar de ellos más ampliamente en otro momento de su discurso: «El general Narváez, de quien todavía he de volver a hablar en estos fragmentos descosidos...» (Estévanez, 89); "[...] que referiré cuando llegue el caso, [sus viajes en barco]» (Echegaray, t. II: 66).

Mas esto no es lo frecuente, la mayoría de las veces los narradores prefieren no adelantar los acontecimientos, sino seguir el curso del relato. Las fórmulas más empleadas recuerdan, como ellos mismos indican, las empleadas en las novelas de folletín: «Pero no anticipemos los sucesos, como dicen en las novelas de folletín» (Echegaray, t. I: 276); «Pero no anticipemos acontecimientos como se dice en las novelas» (Echegaray, t. I: 329); «Los folletines suelen decir: "No adelantemos los sucesos", pero yo los voy a adelantar» (Estévanez, 90); «Pero no adelantemos acontecimientos, como decían los novelistas del antiguo régimen» (Nombela, 90).

La bajada: El relato de los acontecimientos es interrumpido por digresiones de todo tipo en los libros de memorias, con lo cual el narrador ha de volver a tomar el hilo: «Anudando el interrumpido hilo de mi narración, diré, que...» (Alcalá Galiano, t. II: 218); «Pero ahora caigo en que nada de esto es lo que yo quería decir. Vuelvo al punto de partida» (Echegaray, t. II: 3 ); «Otra vez he vuelto a divagar; pero, arre- 
pentido de nuevo, torno al carril» (Ibidem, 6); «Pero sospecho que me voy desviando de mi objeto, y que a este paso nunca llegaré a Londres» (Ibidem, 134); "Abreviemos, [...] es preciso concluir el relato, siquiera sea de lo más esencial» (F. Rubio, 123); «Habrá, pues, que irse a la mano en esto y tratar de avanzar en el relato» (E. Menéndez Pelayo, 178); «Pero sigamos nuestro relato» (Espina, t. II: 172).

Función de comunicación: El aspecto del relato al que se refiere esta función es a la situación comunicativa misma, cuyos dos protagonistas son el narratario y el propio narrador. Recuerda esta función a las funciones fática y conativa de Jackobson (Genette, 1989: 309).

En las memorias estudiadas, la preocupación de los autores por establecer contacto con sus lectores se muestra de una manera evidente. Con frecuencia se dirigen a ellos en las introducciones para ofrecerles su relato y someterlo a su consideración, les comunican su propósito $\mathrm{y}$ apelan a su buen juicio.

Ya las memorias decimonónicas anteriores de carácter histórico, escritas por los políticos y militares, iban precedidas por un largo exordio del autor justificando su propósito al escribir sus memorias. Los motivos que impulsaron a estos autores fueron principalmente dos: dejar un testimonio importante a la posteridad, porque se consideraban protagonistas de la historia; o bien, justificar sus conductas ante sus contemporáneos ${ }^{7}$.

Cuando Patrico de la Escosura, Mesonero Romanos y Zorrilla se deciden a escribir sus memorias a partir de 1876, se dirigen a los lectores en un exordio también justificativo. Pero en este caso su justificación se basa principalmente en su preocupación por «el qué dirán» los lectores cuando vean que quien escribe memorias no es ya un protagonista de la historia, sino un espectador de ella. Sírvannos de ejemplo las declaraciones de Mesonero Romanos:

«Habrá, sin duda, alguno y aun algunos de los que tengan la mala idea de leer estas líneas, que digan, encarándose con el autor: ábranos usted su Memorandum de sus añejas reminiscencias personales; [...] dispuestos estamos a prestarle atención; aunque, a decir verdad, ¿qué interés de novedad han de podernos inspirar los recuerdos de un hombre que, según confesión propia, no ha figurado para nada en el panorama político del país $[. .$.$] ?$

7 Entre sus memorias de carácter justificativo sobresalen las de Godoy, Escoiquiz, Ruiz Zorrilla y José Paul y Angulo. Entre las de carácter informativo, las del Marqués de Miraflores y las de Víctor Balaguer. Para esta cuestión véase Artola (1957). 
Alto ahí, señores míos, contestará el autor; todo lo que ustedes dicen es verdad, pero también lo es que esta misma insignificancia política de su persona, [...] le brinda con mayor dosis de imparcialidad, [...] fijando su atención en los que corresponden a la vida literaria, a que dedicó su especial estudio» (Mesonero, 24).

Mas los autores de memorias no se limitan a dirigirse a los lectores al principio de su narración a modo de prólogo, sino que lo hacen insistentemente a lo largo de todo el discurso. Unas veces, para pedirles disculpas por haberse apartado del objeto principal de la narración, o anunciarles una parada en su relato a causa de las miles de digresiones que intercalan en él. Para ello emplean fórmulas del tipo siguiente: «... resígnese el lector benévolo...» (Escosura, art. III); «Permitido me sea (si no lo ha por enojo el benévolo lector) reposar algún tanto...» (Mesonero, 105); «Séame disculpada la intempestiva digresión...» (Estévanez, 21); «Y ahora dispénsenme los lectores si me he detenido más de lo regular...» (Sanromá, t. I: 229); «Perdóneme el lector: no he de hacer... [...] Los que hayáis tenido la paciencia de leerme sin dejar una línea...» (Sanromá, t. I: 438); «Y perdóneme el lector esta árida y empalagosa digresión» (Echegaray, t. I: 73).

Otras veces, el narrador se muestra preocupado por no despertar el interés de los lectores y, sobre todo, por no aburrirles: «Y si el lector se aburre, que tenga paciencia...» (Echegaray, t. III: 272); «Prepárase pues el lector a aburrirse más que de costumbre...» (Echegaray, t. III: 292); «No temas, oh lector, que te describa...» (Estévanez: 231); « ¿Te aburres, lector querido?» (Vico: 64).

Función testimonial: La orientación del narrador hacia sí mismo se da en las siguientes situaciones comunicativas: cuando indica la fuente de dónde procede su información; cuando indica el grado de precisión de sus propios recuerdos o cuando indica los sentimientos que despiertan en él determinados episodios (Genette, 1989: 310).

En el primer caso, las fórmulas utilizadas por los escritores de memorias suelen ser del tipo: «según oí contar», «de lo que yo fui testigo» o «en los hechos en que tomé parte». Algunos ejemplos, en los que subrayamos las fórmulas, son: «Y cuenta que todo esto lo dice, casi al borde del sepulcro, un testigo imparcial de aquella época» (Mesonero, 291); «Todos los pormenores que he referido, los oía yo contar en mi casa, pero al hombre de la ramilla de jinjolero, al sacerdote librando a su lado y al piquete de tropa, yo los vi, y aquel cuadro para siempre quedóse gradabo en mis ojos. De esto respondo; lo demás lo refiero» 
(Echegaray, t. I: 67); "Soy un testigo que declara en forma escueta los hechos, y nada más que los hechos que presenció» (Echegaray, t. II: 302); «...iré pellizcando de aquello que yo mismo presencié, y referiré los sucesos en que nos tocó el poco envidiable papel de víctimas» (Sanromá, 292).

Más frecuentemente la orientación de los autores se centra en el grado de precisión de los propios recuerdos:

\begin{abstract}
«De la exactitud, no diré matemática, pero sí geométrica, de todos los hechos referidos, yo respondo con toda la seriedad imaginable» (Echegaray, t. I, 67).

«Yo no quiero decir que el diálogo entre el general Prim y yo fuese exactamente, palabra por palabra, el que acabo de dictar al ir evocando mis recuerdos» (Echegaray, t. III, 327).

«En cuanto a que el punto fuese Chalma $u$ otro punto de nombre indio, no estoy yo hoy día muy seguro; porque como después de la muerte de Maximiliano los juristas tropezaron con unos cajones de libros y papeles que a España me venían dirigidos, y con los cuales no he logrado volver a reunirme, escribo estos recuerdos de memoria» (Zorrilla, t. II, 117).
\end{abstract}

La manera de reproducir fielmente «hoy» los hechos y las impresiones de «ayer» es el escollo que tienen que salvar los autores de memorias. Para ello no tienen más que dos caminos: o consultar documentos que estén preparados para ese fin; o bien echar mano de la propia memoria. Dejemos hablar a uno de ellos:

\begin{abstract}
"A medida que avanzo en la redacción de estos Fragmentos de mis Memorias aumentan las dificultades para que en ellos refleje, con una exactitud y fidelidad relativas, el vivir de fondo histórico, real, de los veinte años de Oviedo. Tales dificultades tienen un triple origen. En primer lugar, la desaparición catastrófica, a que ya me he referido de mis documentos [durante la Guerra Civil]. Pensando en escribir algún día - la distracción de viejo- mis Memorias, había yo clasificado cuidadosamente mi copiosísima correspondencia con españoles y extranjeros en unos ochenta paquetes, conservando además otros papeles curiosos, históricos, únicos algunos. En segundo lugar, la debilidad de mis recuerdos que a veces se desvanecen, borran o evaporan, hasta el punto de hacer casi imposible, o imposible del todo, la reconstrucción imaginativa. Por último, la imposibilidad de distinguir o discernir, a esta distancia y en las condiciones que acabo de indicar, lo positivamente vivido, tal como había ido viviendo» (Posada, 186-187).
\end{abstract}

Casi todos los autores estudiados hacen hincapié en que es la memoria la única fuente de la que sacan su materia narrativa, ya que 
no pretenden hacer historia ${ }^{8}$. El autor que más insiste en ello es Mesonero Romanos, quien dice no disponer más que de su prodigiosa memoria para ofrecer la pintura de la ciudad de Madrid entre 1808 y 1850. No nos interesa aquí determinar la veracidad de esta afirmación ${ }^{9}$, sino constatar el hecho de que, en el discurso memorialístico, el narrador reiteradas veces apela al tópico de la memoria cuando quiere disculparse por la posible inexactitud de los acontecimientos narrados: «No lo recuerdo bien; cito de memoria» dice Echegaray frecuentemente. Y, ya se sabe, la memoria falla, y más la de los viejos; y, además, la memoria es selectiva y caprichosa. En estos misterios de la facultad de la memoria se recrean también nuestros escritores, especialmente Echegaray, a quien le encanta reflexionar sobre ello.

Por último, la orientación del narrador hacia sí mismo, en el aspecto más emotivo, se manifiesta cuando se refiere a los sentimientos que despiertan en él —en el yo narrante- determinados episodios ocurridos en el pasado - al yo narrado-. Bástennos las siguientes citas:

«Aun recordado [el hecho de la muerte de su madre], produce en mí más cruel efecto que la memoria de otras desventuras menos naturales y más inesperadas» (Alcalá Galiano, t. I: 442).

«Todavía hoy tiemblo al recordar, a cuyo recuerdo solo, siento helarse mi imaginación y embotarse la pluma en mi mano» (Mesonero, 85).

«Cuando recuerdo la calma y la gravedad de aquella asamblea, el espíritu de tolerancia y abnegación que dominaba en aquellos hombres, [...] no puedo menos de conmoverme y consagrar en mi memoria un respetuoso tributo a tan ilustre asamblea [Las Cortes de 1820]» (Mesonero, 195-196).

«QQué noche pasé! No lo he olvidado durante mi vida, y a pesar de mi vejez que enturbia mi memoria, no se escapa de mi recuerdo un solo detalle [Se refiere a la muerte de un amigo y parte de su familia a causa del cólera]» (Nombela, 403).

«Han transcurrido más de cincuenta y cinco años cuando escribo estas líneas y todavía recuerdo con toda su dolorosa intensidad aquella terrible noche [la de la muerte de su madre]» (Nombela, 193).

8 En esto se diferencian las memorias de nuestro corpus, que son las de los espectadores de la historia, de las memorias escritas por los protagonistas de ella, que presentan un carácter histórico. De ello hablo en el capítulo 2 de mi tesis.

9 El tema de la memoria en Mesonero ha sido tratado por Berkowitz (1930). Según este autor, Mesonero, contrariamente a lo que afirma, extrajo la mayoría de la información de varias fuentes y, además, su memoria más bien flaqueaba, como lo demuestra el hecho del poco espacio que le dedica a los detalles autobiográficos. 
Función ideológica: Las intervenciones del narrador respecto a la historia puedan adoptar también la forma más didáctica de un comentario autorizado de la acción (Genette, 1989: 310).

Esta función está ampliamente cumplida en las memorias. Tanto es así que, en algunos casos, cuantitativamente la parte del relato total que cumple esta función ocupa tanto o más que la que cumple la función puramente narrativa. Incluso, a veces, más. Son poco frecuentes las memorias puramente narrativas.

A diferencia de una novela, donde la función ideológica la pueden desempeñar los diferentes personajes - a quienes encomienda el autor la tarea del comentario y del discurso ideológico-, en las memorias reales, esta función la desempeña en exclusiva el autor-narrador.

Para analizar esta función, tendríamos que distinguir, por un lado, los fragmentos didácticos, en los que los autores de memorias, en su afán de ilustrar la historia, pretenden dar a conocer a los lectores el estado de la cuestión de algunos aspectos determinados y lo hacen de la manera más objetiva posible. Y por otro lado, los fragmentos que encierran un comentario personal de algún acontecimiento o de un personaje público y que, por tanto, dejan traslucir la ideología del autor.

En el primer caso se trata de una forma de discurso explicativo, un verdadero texto de ensayo ${ }^{10}$. Si desgajamos algunos de estos fragmentos de las memorias, nadie podría reconocerlos como integrantes de un libro autobiográfico, incluso desaparece el uso del yo. Solamente antes de comenzar el fragmento y una vez acabado el mismo, el autor toma la voz para señalar su inicio y su final, o para anunciar el principio de otro del mismo estilo:

«Hecha ya esta ligera reseña del Congreso, paréceme del caso proceder a otra igual de la prensa periódica, cual ya lo hice también anteriormente de las sociedades patrióticas [...]; y voy a hacerla con la posible detención y el criterio imparcial e independiente a que siempre obedecin (Mesonero, 196).

10 En las memorias estudiadas, los fragmentos discursivos de este tipo abarcan una gama temática muy amplia, aunque principalmente podemos hablar de tres campos: la política, la sociedad y la cultura. El periodismo, las tertulias, el funcionamiento de las Cortes, la educación y la vida literaria de la época, son algunos de los temas más tratados. Estos temas los he desarrollado en el capítulo 5 de mi tesis. 
En segundo lugar, la función ideológica la cumplen también los autores de memorias al desarrollar esa forma de discurso justificativo que constituye muchas de las introducciones, como hemos visto al hablar de la función de comunicación.

\section{CONCLUSIÓN}

Si comparamos el discurso memorialístico con el discurso autobiográfico de ficción, podemos decir que se observan las siguientes diferencias: en las novelas autobiográficas tradicionales, predomina el nivel de lo narrado; la actividad narrativa se orienta más hacia el objeto (acción narrada o historia) que hacia el proceso mismo de la narración o enunciación; el narrador presta poca atención a los problemas de la narración, y menos aún al proceso de la actividad memorística; la narración sigue la lógica de una memoria en actividad. Asimismo, en el relato autobiográfico de ficción tradicional, el momento de la narración no pertenece a la acción contada. La situación del narrador es en la mayoría de los casos indeterminada. El narrador no refiere casi nunca los detalles de su aventura narrativa.

Por el contrario, en las memorias reales, la actividad narrativa se orienta, a menudo, hacia el proceso de enunciación o narración. La orientación del autor-narrador se vuelve continuamente hacia el momento de la narración, refiriéndose frecuentemente a los detalles de su aventura narrativa. Los problemas de la narración - y más aún el proceso de la actividad memorística-, y el acto narrativo mismo están fuertemente tematizados.

En definitiva, el relato de las memorias (como todos los géneros autobiográficos) es rico en elementos que pertenecen al nivel del discurso: el autor habla frecuentemente de su propia situación, de sus emociones, de la enunciación misma, o de la actividad narrativa misma. 


\section{Referencias bibliográficas}

Alonso, Amado (1969). «Un problema estilístico de D. Segundo Sombras». En Materia y forma en poesía, 355-363. Madrid: Gredos.

Artola, Miguel, ed. (1957). Memorias de tiempos de Fernando VII. Edición y estudio preliminar de M. Artola, Madrid, Atlas, BAE núms. 97 y 98, 2 vols.

BARTHES, R. (1967). «Le discours de l'histoire». Social Science Information. Information sur les sciences sociales, VI, 4.

Benveniste, E. (1988). Problemas de lingüística general. Madrid: Siglo XXI.

Berkowitz, CH. (1930). «El elemento Memoria en las Memorias de Mesonero Romanos». The Romanic Review, XXI.

CABAllé, Ana (1986). La literatura autobiográfica en España (1939-1979). Tesis Doctoral, Universidad de Barcelona.

- (1987). «Figuras de la Autobiografía». Revista de Occidente 74-75, 103 119 (julio-agosto).

- (1991). «Memorias y autobiografías en España (siglos XIX y XX)». Suplementos Anthropos 29, 143-169.

FERnÁndez, James (1991). «Textos autobiográficos españoles de los siglos XVIII, XIX y XX. Bibliografía». Anthropos 125, octubre, 20-23 (Monográfico, bajo el tema: La Autobiografía en la España contemporánea).

G. LOUREIRo, Ángel (1991). «La autobiografía española: actualidad y futuro». Anthropos 125, octubre, 17-19.

- (1991). «Problemas teóricos de la autobiografía». Suplementos Anthropos 29, diciembre, 2-8.

- (1991). «Bibliografía selecta sobre teoría de la autobiografía». Suplementos Anthropos 29, 137-142.

- (1991). «Bibliografía general sobre la autobiografía española». Suplementos Anthropos 29, 142-143.

GenetTe, Gérard (1983). Nouveau discours du récit. París: Seuil.

- (1989). «Discurso del relato». En Figuras III. Barcelona: Lumen.

GuSDORF, Georges (1991). Les écritures du moi. París: Éditions Odile Jacob.

JAKOBSON, Roman (1966). Problèmes du langage. París: Gallimard.

LEJEUNE, Philippe (1975). Le pacte autobiographique. París: Seuil.

LozANo, Jorge (1987). El discurso histórico. Madrid: Alianza Editorial.

MATEOS, Aurora (1994). Memorias del siglo XIX (1875-1914) como fuente de información lingüística y literaria. Tesis Doctoral. Publicada en microfichas por Publicacions de la Universitat de Barcelona.

MUSARR-SCRøDER, U. (1981). Le roman-mémoires moderne. Pour une typologie du rècit à la première personne. Amsterdam \& Maarssen:. Apa-Holland University Press. Tesis doctoral leída en la Universidad de Nimègue en 1981.

Romera Castillo, José. (1980). «La autobiografía como género literario». Revista de Investigación (Colegio Universitario de Soria) IV-1, 279-294.

- (1991). «Panorama de la literatura autobiográfica en España (19751991)». Suplementos Anthoropos 29, diciembre, 170-181.

ROMERA, J. et alii (1993). Escritura autobiográfica. Madrid: Visor Libros.

YlleRA, Alicia. (1981). «La autobiografía como género renovador de la novela». 1616. Anuario de la Sociedad Española de Literatura General y Comparada IV, 164-191. 


\section{APÉNDICE}

\section{Memorias que constituyen el corpus}

En la presente bibliografía, ofrecemos las distintas ediciones y reimpresiones de las memorias que constituyen el corpus. Marcamos con un asterisco $(*)$, colocado delante, la edición que hemos manejado en el presente trabajo, en los casos en los que existan varias ediciones.

Alcalá Galiano, AnTonio. Recuerdos de un anciano. Madrid: Imprenta Central, 1878. (Habían sido publicados como artículos sueltos en La América, 1862-64). Varias reimpresiones: *Madrid, 1890; Madrid, 1907; Madrid, 1927. Madrid: Biblioteca de Autores Españoles, 1955, en edición de Jorge Campos.

- Memorias de D. Antonio Alcalá Galiano, publicadas por su hijo, 2 vols., Madrid: Imprenta de E. Rubiños, 1886. Reimpreso en edición de Jorge Campos, en *Madrid: Biblioteca de Autores Españoles, vols. 83 y 84, 1955. Existe una reimpresión de una selección, con el mismo título, en Madrid, Espasa Calpe, 1951.

ARDERÍUS, FRANCISCO. De mis recuerdos. Narraciones históricas. Madrid, 1914.

Autobiografias y Memorias, coleccionadas e ilustradas por Manuel Serrano y Sanz. Madrid: Nueva Biblioteca de Autores Españoles, 1905.

Ayerbe, MARqués DE. «Memorias del Marqués de Ayerbe sobre la estancia de Fernando VII en Valençay y el principio de la guerra de independencia». En Memorias de tiempos de Fernando VII, vol. I, 227-273. Madrid, 1957, Biblioteca de Autores Españoles, vols. 97 y 98, edición de M. Artola.

AzCÁRATe, Gumersindo DE. Minuta de un testamento. Madrid, 1876. *Edición de Elías Díaz en Madrid: Cultura Popular, 1967.

BALAguer, Víctor. Memorias de un constituyente. *Madrid: Librería de Medina y Navarro, 1873 (en el mismo volumen se encuentran también otros trabajos). Reimpreso en Madrid, 1874.

Barbasán y Laguernela, CASto. Memorias de un defensor. 2 vols., Madrid: Biblioteca de «Los estudios militares», 1897.

Benalúa, Conde De. Memorias del..., Duque de San Pedro de Galatino, vol. I. Madrid: Imprenta de Pueyo, 1924.

Blanco White, JosÉ. The Life of the Reverend Joseph Blanco White. Written for himself, 3 vols. Londres: Chapman, 1845. Hay traducciones de fragmentos en J. Goytisolo, Obra inglesa de don José Blanco White, Barcelona, 1974 y en *Antonio Garnica, Autobiografía de Blanco White, Sevilla: Universidad de Sevilla, 1975.

Blasco, Eusebio. Memorias intimas. *Madrid, 1904, en Obras Completas de D. Eusebio Blasco, vol. IV. Se habían publicado antes, el 29 de enero de 1898, en El Heraldo de Madrid (transcripción de las conferencias pronunciadas en el Ateneo ese mismo año).

- Mis contemporáneos. Madrid, 1886. Reimpresión en Obras Completas, vol. XIII, Madrid, 1903-1906.

CASA VAlenCIA, Conde DE. (Emilio Alcalá Galiano). Recuerdos de la juventud. Mis dos viajes a América. Madrid: Estab. Tip. de Fortanet, 1898.

Conte, Augusto. Recuerdos de un diplomático. 3 vols. Madrid: Imprenta de J. Góngora y Álvarez, 1901-1903. 
ECHEgARAY, JosÉ. Recuerdos. *Madrid, 1917. 3 vols. Fueron publicados primeramente en artículos en dos revistas: La España Moderna, 1894-97, y en El Madrid científico. Reimpresión, Madrid, 1949.

ESCOIOUIZ, JUAN DE. Idea sencilla de las razones que motivaron el viaje del Rey Don Fernando VII a Bayona y de Europa por el Excmo. Sr. D... Incluidas en Memorias de tiempos de Fernando VII. vol. 97 de la Biblioteca de Autores Españoles, de M. Artola, Madrid, 1957.

- Las memorias de D. Juan de Escoiquiz, en Memorias de tiempos de Fernando VII, vol. 97.

ESCOSURA, PATRICIO DE LA. «Recuerdos literarios. Reminiscencias biográficas del presente siglo». La Ilustración Española y Americana, Madrid, 1876.

EsPINA Y CAPO, ANTONIO. Notas del viaje de mi vida, 3 vols. Madrid: Talleres Calpe, 1926-1929.

EsPoz Y MiNA, CONDESA DE (Juana María de la Vega). Apuntes para la historia del tiempo que ocupó los destinos de Aya de S.M. y Aya y Camarera Mayor de Palacio. Escritos inmediatamente después de mi renuncia (18411843) y En honor de Mina. Memorias íntimas (1820 a 1836), inéditas hasta que fueron publicadas en un solo volumen, Madrid, 1910. En honor... fue reimpreso en la Biblioteca de Autores Españoles, Madrid, 1962, en edición de M. Artola. Todo el conjunto ha sido reimpreso por *Tebas, con el título de Memorias, y con prólogo de la Condesa de Campo Alange, Madrid, 1977.

ESTEVÁNEZ MURPHY, NiCOLÁs. Fragmentos de mis memorias. Madrid: Hijos de R. Álvarez, 1903. Fueron publicadas en artículos en El Imparcial, en 1899. Han sido reimpresas con el título de Mis memorias, Madrid: Bordón, 1947 y en *Tebas con prólogo de J. L. Fernández-Rúa, Madrid, 1975.

FERNÁNDEZ de CóRdova, FERNANDO. Mis memorias íntimas, 3 vols. Madrid, 1886-1889 (reimpreso varias veces: en Madrid, 1899-1903, en 3 vols.; en Madrid, 1835, en 1846 y en 1850). *Edición de M. Artola, en la Biblioteca de Autores Españoles, vols. 192 y 193, Madrid, 1966.

Gracia de León y PIZARRo, J. Memorias de la vida del Excmo. Sr..., escritas por él mismo. 3 vols. Madrid: Col. Escritores Castellanos, vols. 104, 109 y 112, 1894-1897. Reimpresas en edición, prólogo, notas y apéndices de Álvaro Alonso Castrillo, Madrid: Revista de Occidente, vol. I, 1953.

Godoy Álvarez de FARIA, MANUEl. Cuenta dada de su vida política por don..., príncipe de la paz, o sea, memorias críticas y apologéticas para la historia del reinado del señor don Carlos IV de Borbón, 6 vols. Madrid, 18361842. Reimpresiones en Gerona, 1839, y en Madrid, 1908. *Edición de C. Seco Serrano, con el título de Memorias, en la Biblioteca de Autores Españoles, vols. 88 y 89 , Madrid, 1956.

GómEZ DE AVEllanedA, GeRTRUdis. Autobiografía y cartas de la ilustre poetisa, hasta ahora inéditas. Edición de L. Cruz de Fuentes. Huelva, 1907. Con el título de Memorias inéditas de la Avellaneda, se publicó en *La Habana: Siglo XX, anotado por Domingo Figuerola, en 1914. Con el título de Diálogo de amor y con prólogo, ordenación y notas de A. Ghiraldo, Madrid: Aguilar, 1928. Recientemente han sido reeditadas en la *Ed. Castalia/Instituto de la Mujer, Poesías y epistolario de amor y de amistad, edición, introducción y notas de Elena Catena, Madrid, 1989; y por *Nora Catelli como apéndice de su libro El espacio autobiográfico, Barcelona: Lumen, 1991. 
GonZÁlez ARACO, M. El teatro Real por dentro, memorias de un empresario. Madrid: Imprenta de los Hijos de José Ducazcal, 1897. 2. ed. en 1892 y reimpresión de 1907. Nuevas ediciones en Madrid, 1930 y 1949.

Hortelano, Benito. Memorias de... Madrid: Espasa-Calpe, 1936.

Menéndez Pelayo, EnRIQUe. Memorias de uno a quien no sucedió nada. Santander: Librería Nacional y Extranjera, 1922. *Nueva edición con introducción, biografía y notas de Benito Madariaga, Santander: Ediciones de Librería Estudio, 1983.

MESONERo Romanos, RAMÓN. Memorias de un setentón. Madrid, 1880 (publicadas originalmente en La Ilustración Española y Americana, de 1878 a 1879). Nueva edición aumentada, en la misma editorial, Las Oficinas de La Ilustración, en 1881. Existen varias ediciones posteriores: Madrid: Renacimiento, 1926; Madrid: Ed. Guzmán, 1948 (reimpresión en 1955); Madrid: Ed. Mediterránea, 1948; Madrid: Vindel, 1950; Madrid: Librería Iberoamericana, 1955; Madrid: Publicaciones Españolas, 1961; Biblioteca de Autores Españoles, ed. y estudio preliminar por Carlos Seco Serrano, Madrid, 1967; y Madrid: *Tebas, 1975.

MIRAFLORES, MARQUÉS DE. Memorias para la historia contemporánea de los siete primeros años del reinado de Isabel II. Madrid, 1843-1844 (reimpreso en Madrid, 1934). Madrid: Ed. Bardón, 1953. Madrid: Ed. Pavill, 1954. *Madrid: Biblioteca de Autores Españoles, vols. 172 y 173, en edición de Manuel Fernández Suárez, 1964.

MOR DE Fuentes, J. Bosquejillo de la vida y escritos de D. José Mor de Fuentes delineado por él mismo, Barcelona, 1836, editado por el librero Antonio Bergnes. Reeditado en Madrid por la editorial Peiró, 1950. *Edición de M. Artola, Madrid: Biblioteca de Autores Españoles, vol. 97, pp. 373-428, 1957. Existe otra edición de M. Alvar en Zaragoza: Guara, 1981.

Nombela, Julio. Impresiones y recuerdos. 4 vols., Madrid: Casa Editorial de la Última Moda, 1909-1911 (2. a edición en 1920, y otras sucesivas en 1936, 1950 y 1955). *Reimpreso en un solo tomo, Madrid: Tebas, 1976, con prólogo de Jorge Campos.

PALACIO, MANUEl DE. Páginas sueltas. En El Lunes de El Imparcial, Madrid, 1902.

PARDO BAZÁN, EMILIA. «Apuntes autobiográficos». Barcelona: Daniel Cortezo, 1886 (preceden a la primera edición de Los pazos de Ulloa). Reeditados en *Obras Completas, vol. III, Madrid: Aguilar, 1973, 698-732.

PaUl y Angulo, José. Memorias íntimas de un pronunciamiento. *Madrid, 1869. Reimpresiones: Madrid: Ed. Parnasillo, 1954 y Madrid: Librería Central, 1956.

PÉrez Galdós, Benito. Memorias de un desmemoriado. Madrid: Alhambra, 1920 (publicado anteriormente como artículos en la revista La Esfera, 1916). Reimpresión en sus Obras inéditas, vol. 10, Madrid: Renacimiento, 1930; también en *Obras Completas, vol. 3, Novelas y Miscelánea, Madrid: Aguilar, 1973, 1430-1473 y en *Madrid: Tebas, 1975, junto con otros escritos, bajo el título de Recuerdos y Memorias.

PosAdA, ADOLFo. Fragmentos de mis memorias. Oviedo: Universidad de Oviedo, 1983, con prólogo de Emilio Alarcos Llorach (inéditas hasta esta fecha).

RAMÓN Y CAJAL, SANTIAgo. Mi infancia y juventud, Madrid: Imprenta de Pueyo, 1923. Reimpreso en Buenos Aires: Espasa Calpe Argentina, a partir de 1939; *la undécima ed. en Madrid, 1989. 
- Recuerdos de mi vida. Madrid, 1901. Madrid: Imprenta de Fortanet, 1917. Madrid: Imprenta de Pueyo, 1923.

Roure, CONRADO. Recuerdos de mi larga vida; costumbres anécdotas y sucesos acaecidos en la ciudad de Barcelona, desde el 1850 hasta el 1900, 3 vols. Barcelona: Biblioteca de El Diluvio, 1925-1927 (publicados previamente como artículos en la revista El Diluvio).

RuBIO Y GALÍ, FEDERICO. Mis maestros y mi educación. Memorias de niñez y juventud: Madrid-Sevilla, 1912, publicado por su hija. Reeditado en *Madrid: Tebas, 1977, con prólogo de Pedro Laín Entralgo.

Ruiz CONTRERAS, LUIS. Memorias de un desmemoriado, 2 vols. Madrid: Sociedad Española de Librerías, Diarios, Revistas y Publicaciones, 1917. Reeditadas en *Madrid: Aguilar, 1945.

RUIZ ZORRILlA, MANUEl. A sus amigos y a sus adversarios. Madrid, 1877. Varias impresiones: Madrid: Biblioteca Democrática, 1882; *Barcelona: Biblioteca del Pueblo (folleto), 1885; Madrid: Ed. Molina, 1941; Madrid: Ed. Mat. Ortega, 1952 y 1960; y Espasa Calpe, 1958.

SANROMÁ, JOAQUín MARÍA. Mis memorias, 2 vols. *Madrid: Tipografía de Manuel G. Hernández, 1887-1894 (habían sido publicadas con anterioridad en la Revista Contemporánea, 1886-1887), $2 .^{\mathrm{a}}$ ed. 1924. Reimpreso en Madrid: Ed. Melchor García, 1954.

SOMOZA, JosÉ. «Artículos autobiográficos». En Obras en prosa y verso, Madrid: Imprenta de la Revista de Archivos, Bibliotecas y Museos, 1904. Bajo el título de Recuerdos e impresiones de Somoza, el *Marqués de Valmar recoge algunos artículos en la Biblioteca de Autores Españoles, vol. 67.

TABOADA, LUIS. Intimidades y recuerdos (Páginas de la vida de un escritor). Madrid: Administración de El Imparcial, 1900.

UnAMUNo, Miguel DE. Recuerdos de niñez y mocedad. Madrid: V. Suárez, 1909. Reimpreso en Buenos Aires: Espasa Calpe Argentina, 1942; y en *Madrid: Tebas, 1975, junto con Publicidad e intimidad.

VALERO DE TORNOS, JUAN. Crónicas retrospectivas (recuerdos de la segunda mitad del s. XIX por un portero del observatorio). Madrid: Imprenta de Ricardo Rojas, 1901, con prólogo de J. Octavio Picón. Existen varias ediciones en el s. XX: Madrid, 1958; Madrid: Mat. Ortega, 1952; Madrid: Monterrey, 1965 y Madrid: Bordón, 1968.

Vico, Antonio. Mis memorias (Cuarenta años de cómico). Madrid: Serrano Editor, 1902.

VillanUEVA, JoAQUín LORENZo. Vida literaria de D. Joaquín Lorenzo Villanueva, o Memoria de sus escritos y de sus opiniones eclesiásticas y políticas, $y$ de algún suceso notable de su tiempo [...] Escrito por él mismo, 2 vols. Londres: Dulau, 1825. Parte de ellas están reproducidas en *Memorias de tiempos de Fernando VII, vol. II, Madrid: BAE, 1957.

ZoRRILlA, JosÉ. Recuerdos del tiempo viejo, 3 vols. Barcelona: Imprenta de los Sucesores de Ramírez, 1880 (publicado primeramente en artículos en Los Lunes de El Imparcial en 1879 y 1880), 2. ${ }^{a}$ ed. aumentada, en Madrid, 1880, 2 vols. Reimpreso en 3 vols., Madrid: Tip. Gutenberg, 1882. En Obras Completas, Valladolid: Librería Santarén, 1943, 1729-2097. *Madrid: Publicaciones Españolas, 2 vols., 1961 y Madrid: Rodríguez Muñoz, 1963. 